\title{
Prolonged treatment of pulmonary sarcoidosis with corticosteroids
}

\author{
CLIFFORD HOYLE, HUGH SMYLLIE ${ }^{1}$, AND DAVID LEAK
}

From King's College Hospital, London

\begin{abstract}
The results are described of prolonged corticosteroid treatment in 52 patients with pulmonary sarcoidosis observed for a mean duration of 10.5 years from diagnosis. Twenty of the patients were treated for less than one year, the remainder for a mean of five years. The mean length of observation after discontinuing treatment was 5.5 years. Selection of patients for treatment was based on (1) evidence from radiographic observation, even for two years or more, that the disease was progressive so that spontaneous remission was improbable; and (2) evidence of disturbed lung function, especially the onset of dyspnoea or an impaired diffusing capacity. Treatment, conveniently with prednisone at a maintenance dose of about $15 \mathrm{mg}$. daily, should be continued for at least a year and often for much longer until withdrawal is not followed by radiographic relapse. Such treatment does not increase the chance of a complete remission even when given at an early stage of the disease ; and relief of dyspnoea is unpredictable and seldom considerable. But prolonged treatment will halt progressive lung destruction and appears to curb the eventual mortality.
\end{abstract}

Corticosteroids are well known to suppress the follicles of sarcoidosis and to improve the chest radiograph when the lungs are actively affected. Whether they can arrest progressive pulmonary sarcoidosis or alter its course in the long run, let alone reduce its mortality, has yet to be shown. While a controlled trial might supply the answer, we doubt whether the results could be reliable. Even with a large series of patients available, relatively few need treatment and, among those who do; the disease evolves so slowly in this country that many years would pass before statistics could be collected. What we have done instead is to compare, over a few years, the outcome in a small group of treated patients with that in a similar untreated group seen shortly before corticosteroids became available and who had already been reported (Smellie and Hoyle, 1960).

\section{MATERIAL AND METHODS}

This report concerns 52 treated patients who began corticosteroid treatment before 1960 and 77 who were not treated and have been reported previously (Smellie and Hoyle, 1960). Twenty of the former group were first reported in 1955 (Hoyle, Dawson, and Mather, 1955) after receiving short courses of cortisone when

1 Requests for reprints should be sent to H.S., Royal Infirmary, Doncastér it was introduced. Some of these have been treated again for longer periods and are included for comparison of their eventual outcome with that of untreated patients. Twenty of the 52 patients were treated for less than a year, the remaining 32 for longer, with a mean of 5 years (range 1 to $13 \cdot 7$ years). We did not attempt to standardize the time, preferring to decide for each patient on the merits of his case. The mean length of observation from the time of discontinuing steroid treatment in those patients in whom this was possible was 5.5 years (range 1.7 to 11 years).

Initial investigation was made in the usual way and histological evidence of sarcoidosis was found in 46 patients. Dyspnoea was measured before and after treatment by grades already described (Smellie, Apthorp, and Marshall, 1961). The 52 treated patients were observed for a mean duration of 10.5 years (range 2 to 25 years). They were treated solely for their lung disease, except 13 with ocular sarcoidosis and three with hypercalcaemia whose lungs or hilar lymph nodes were also affected.

Treatment was usually started in hospital with a daily dose of $150 \mathrm{mg}$. cortisone (26 patients) or $30 \mathrm{mg}$. prednisone (26 patients). Chest radiographs were taken monthly at first. When maximum improvement was found-in about three months as a rule-the corticosteroid was reduced gradually by monthly steps of 10 to $20 \mathrm{mg}$. cortisone or 2.5 to $5 \mathrm{mg}$. prednisone to a maintenance level of about 50 to $75 \mathrm{mg}$. cortisone or 10 to $15 \mathrm{mg}$. prednisone daily. Occasionally as little as $5 \mathrm{mg}$. prednisone was found to be enough. 
The effects of treatment, and of relapse when treatment was stopped, were judged mainly by radiographic changes, dyspnoea, and lung function. The mortalities of the treated and untreated groups were also compared.

\section{RESULTS}

RADIOGRAPHIC COURSE A straight comparison between the radiographic course of 52 treated patients and 77 untreated ones (from Smellie and Hoyle, 1960) in Table I shows that fewer treated patients achieved radiographic clearing.

\section{T A B L E I}

COMPARISON OF RADIOGRAPHIC COURSE OF 52 PATIENTS TREATED WITH CORTICOSTEROIDS WITH THAT $\begin{array}{r}\text { OF } 77 \text { UNTREATED PATIENTS } \\ \hline\end{array}$

\begin{tabular}{|c|c|c|c|}
\hline Radiograph & & Treated & $\begin{array}{c}\text { Untreated } \\
\text { (Smellie and Hoyle, 1960) }\end{array}$ \\
\hline $\begin{array}{ll}\text { Clear } & \ldots \\
\text { Unproved } & \ldots \\
\text { Unchanged or worse }\end{array}$ & $\begin{array}{l}\cdots \\
\cdots\end{array}$ & $\begin{array}{l}12 \\
16\left(^{(1} \text { dead }\right)^{1} \\
24 \text { (6 dead })^{1}\end{array}$ & $\begin{array}{l}39 \\
8 \\
30\end{array}$ \\
\hline
\end{tabular}

${ }^{1}$ Died of chronic renal failure

Failure to improve, or even deterioration, was commoner in the treated group. This was a false impression, however, for the treated group included some who had advanced disease when given short courses of treatment; and also some who were treated initially within two years of discovery of their disease, a period within which spontaneous remission is now well known to occur (Smellie and Hoyle, 1960). If the outcome for patients treated within two years of discovery is compared with that of the untreated group (Table II) then it can be inferred that treatment did not increase the chance of full remission.

T A B L E I I

RADIOGRAPHIC COURSE OF 22 PATIENTS TREATED WITHIN 2 YEARS OF DISCOVERY AND 77 UNTREATED PATIENTS

\begin{tabular}{|c|c|c|c|}
\hline Radiograph & & Treated & $\begin{array}{c}\text { Untreated } \\
\text { (Smellie and Hoyle, 1960) }\end{array}$ \\
\hline $\begin{array}{l}\text { Clear } \quad . \\
\text { Improved } \quad \ldots \\
\text { Unchanged or worse }\end{array}$ & $\begin{array}{l}\cdots \\
\cdots\end{array}$ & $\begin{array}{l}10 \\
6 \\
6 \\
(1 \text { dead })\end{array}$ & $\begin{array}{l}39 \\
8 \\
30\end{array}(5$ dead $)$ \\
\hline
\end{tabular}

Table III gives a further comparison between long-term treated and untreated patients who had had abnormal pulmonary shadows for more than three years from discovery. Here improvement is shown to occur with treatment (8 of 15) where no improvement had occurred naturally ( 0 of 27 ). Also, it seems likely from the fewer deaths from lung failure (1. of 15$)$ that these patients gained
T A B L E I I I

COMPARISON OF 15 PATIENTS TREATED FOR MORE THAN A YEAR AFTER OBSERVATION FOR THREE YEARS AND 27 UNTREATED PATIENTS FOUND TO HAVE PUL MONARY LESIONS PERSISTING FOR THREE YEARS

\begin{tabular}{|c|c|c|c|c|c|c|}
\hline \multicolumn{5}{|c|}{ Radiegraph } & Treated & Untreated \\
\hline $\begin{array}{l}\text { Clear } \\
\text { Improved } \\
\text { Unchanged } \\
\text { Worse }\end{array}$ & $\begin{array}{l}\ldots \\
\cdots \\
\cdots\end{array}$ & $\begin{array}{l}\ddot{*} \\
\ddot{*} \\
\dot{*}\end{array}$ & $\begin{array}{l}\cdots \\
\cdots \\
\cdots\end{array}$ & $\begin{array}{l}\cdots \\
\cdots \\
\cdots\end{array}$ & $\begin{array}{l}0 \\
8(1 \text { dead })^{1} \\
3 \\
4(1 \text { dead })\end{array}$ & $\begin{array}{c}0 \\
0 \\
6 \\
21 \text { (5 dead })\end{array}$ \\
\hline
\end{tabular}

1 Died of chronic renal failure

lasting benefit as opposed to mere radiographic $N$ improvement. Further deaths may occur, but this or group has already been under surveillance for $a \stackrel{G}{\circ}$ mean time of 14.5 years, as opposed to the mean of 4 years for the untreated series.

EFFECT OF CORTICOSTEROIDS ON DYSPNOEA Dyspnoea on exertion is the chief symptom of $\Phi$ progressive pulmonary sarcoidosis. Thirty-three $\frac{\partial}{0}$ of our 52 patients complained of this. Only eight $\stackrel{\mathbb{}}{-}$ had any symptomatic relief during treatment and $\vec{\varphi}$ only four claimed complete relief, a disappointing $\mathscr{\sigma}$ result even allowing that 23 of the 33 already had some radiographic evidence of pulmonary fibrosis. Among the few who gained relief this was unrelated to radiographic improvement. Indeed, five of the eight patients who were improved had less $\frac{\circ}{\varnothing}$ than $50 \%$ clearing of their shadows and one was $\varrho$ unchanged.

The results of lung function studies in some of these patients have already been reported (Marshall, Smellie, Baylis, Hoyle, and Bates, 1958 ; Smellie et al., 1961 ; Hamer, 1963).

RELAPSE ON WITHDRAWAL OF TREATMENT When treatment was stopped or reduced excessively, 34 3 of 47 patients showed radiographic evidence of subsequent relapse. Nine of these had failed to $\frac{\rho}{3}$ show any improvement, so that the appearances

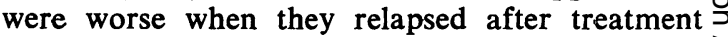
than they were before. In an attempt to explain $\frac{D}{O}$ why some patients did not relapse after withdrawal of corticosteroids we have analysed the $N$ presence or absence of relapse in relation to (1) the presence of pulmonary fibrosis before treat- $N$ ment began; (2) the maximum therapeutic effect $\omega$ on the pulmonary lesions; (3) the known duration of the disorder before treatment; (4) the duration 0 of treatment; and (5) the extent of the disease $\overparen{D}$ judged by the presence of extrapulmonary lesions.

Table IV gives the significant findings. While $\frac{7}{0}$ no patient relapsed who achieved complete radio- $\frac{O}{\mathbb{D}}$ graphic clearing during treatment, those with considerable radiographic improvement short of $\stackrel{\mathbb{Q}}{\mathscr{Q}}$ 


\section{T A B LE IV}

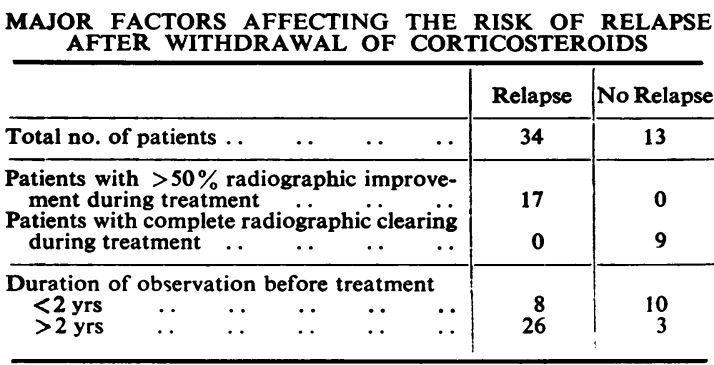

clearing all relapsed. Further, there was a greater chance of relapse if treatment began more than two years from the time of first diagnosis. This applied also if treatment continued for more than a year, an anomalous finding not included in Table IV which will be discussed later. No relationship was found between relapse and the presence of pulmonary fibrosis or the extent of extrapulmonary lesions. With regard to extrapulmonary sarcoid, however, it should be noted that although the chest radiograph may have cleared and the extra-pulmonary lesion have been suppressed by steroids, the latter may relapse when steroids are discontinued, although the chest radiograph remains clear: this occurred in four of our patients with uveitis and pulmonary sarcoidosis.

SIDE-EFFECTS OF CORTICOSTEROID TREATMENT Twelve of the 52 patients had notable complications from their treatment, which were serious in three. One had left ventricular failure complicating steroid-induced hypertension, one a collapsed vertebra, and one severe depression. Mild hypertension and Cushingoid appearance were the commonest side-effects, with obesity and dyspepsia occurring less often.

\section{DISCUSSION}

The main conclusions to be drawn from this survey are $(a)$ that corticosteroid treatment may relieve dyspnoea due to the pulmonary lesions of sarcoidosis, but in a minority only; (b) that it does not increase the chance of complete remission; and (c) that prolonged treatment with corticosteroids appears to modify the course of progressive pulmonary sarcoidosis.

About a quarter of our patients taking corticosteroids who had dyspnoea were relieved. The relief was never dramatic, nor was it related either to the degree of radiographic improvement or to improvement in lung function (Smellie et al., 1961). Grievous dyspnoea has been proposed as an indication for using corticosteroids (American Thoracic Society, 1960 ; Scadding, 1961), but we are convinced that this is worth while only in so-called alveolar capillary block due to acute sarcoidosis as seen chiefly in North America. Patients with severe pulmonary fibrosis in our hands have not improved. There is a chance of relief with lesser grades attributable to infiltration or to less severe fibrosis, although these imply some permanent lung damage. But then the aim is rather the prevention of further fibrosis and its complications and not just the relief of dyspnoea, which a minority only will experience.

It is agreed generally that corticosteroids have no more than a suppressive action on the epithelioid cell follicle of sarcoidosis. The main evidence is that complete radiographic clearing of shadows due to these lesions does not occur more often in patients treated with corticosteroids than would be expected from what we know of the natural course of the disorder (Tables I and II). Scadding (1961), James (1961), and Sones and Israel (1961) have made similar observations. There is other evidence also; for we found relapse to be the rule among patients whose chest radiographs showed improvement short of complete clearing after withdrawal of corticosteroids (Table IV), while those achieving complete clearing did not relapse, presumably because their disease remitted spontaneously. This assumption is supported by the significantly greater risk of relapse among patients treated after preliminary observation for two years, who are therefore unlikely to undergo spontaneous remission. That patients treated for more than a year had a greater risk of relapse is probably another expression of this principle : 21 of the 22 in this category who relapsed were observed for more than two years before treatment, but only two of the five who did not relapse.

About half our patients (28 of 52) improved radiographically to. a varying degree (Table I). Stricter comparison with an untreated series showed that, of those who were treated, about half improved radiographically, but none of those who were untreated (Table IV). Moreover, only one of the treated patients has died of respiratory failure, compared with five of the untreated. While this untreated group may not be regarded as a control series in the strict sense, it merits comparison for two reasons: (a) both groups were first followed for three years in which they were found to have persisting pulmonary lesions, thus virtually excluding the possibility of spontaneous 


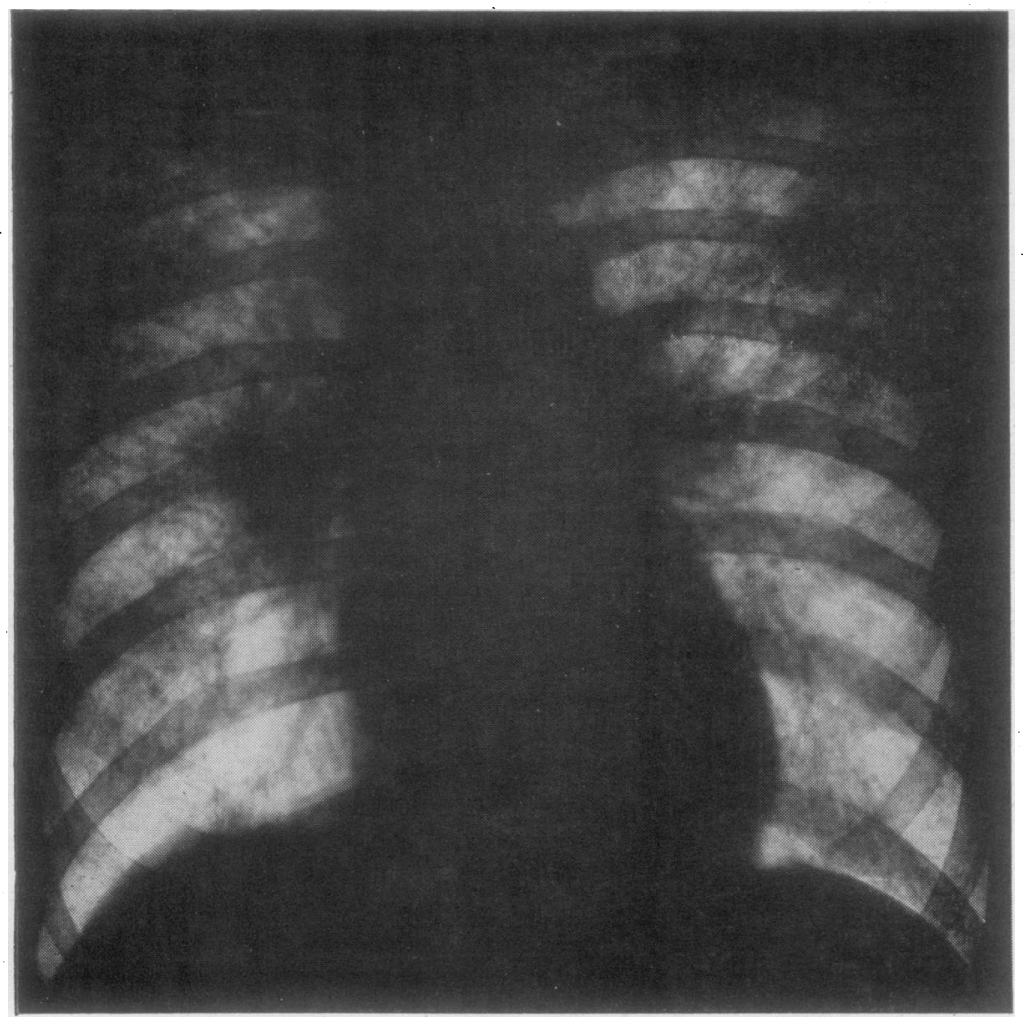

FIG. 1. Pre-treatment chest radio or graph.

FIG. 2. Improvement after one year's treatment with prednisone.

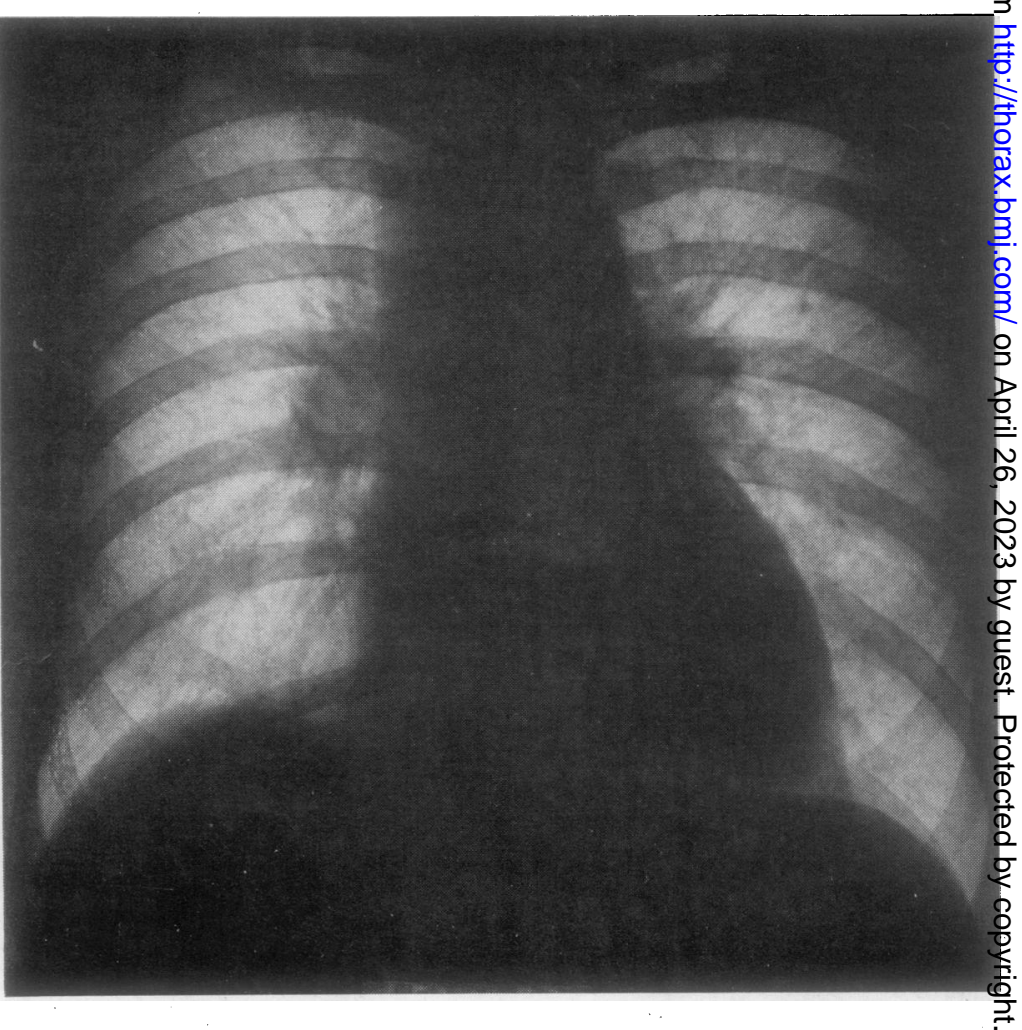




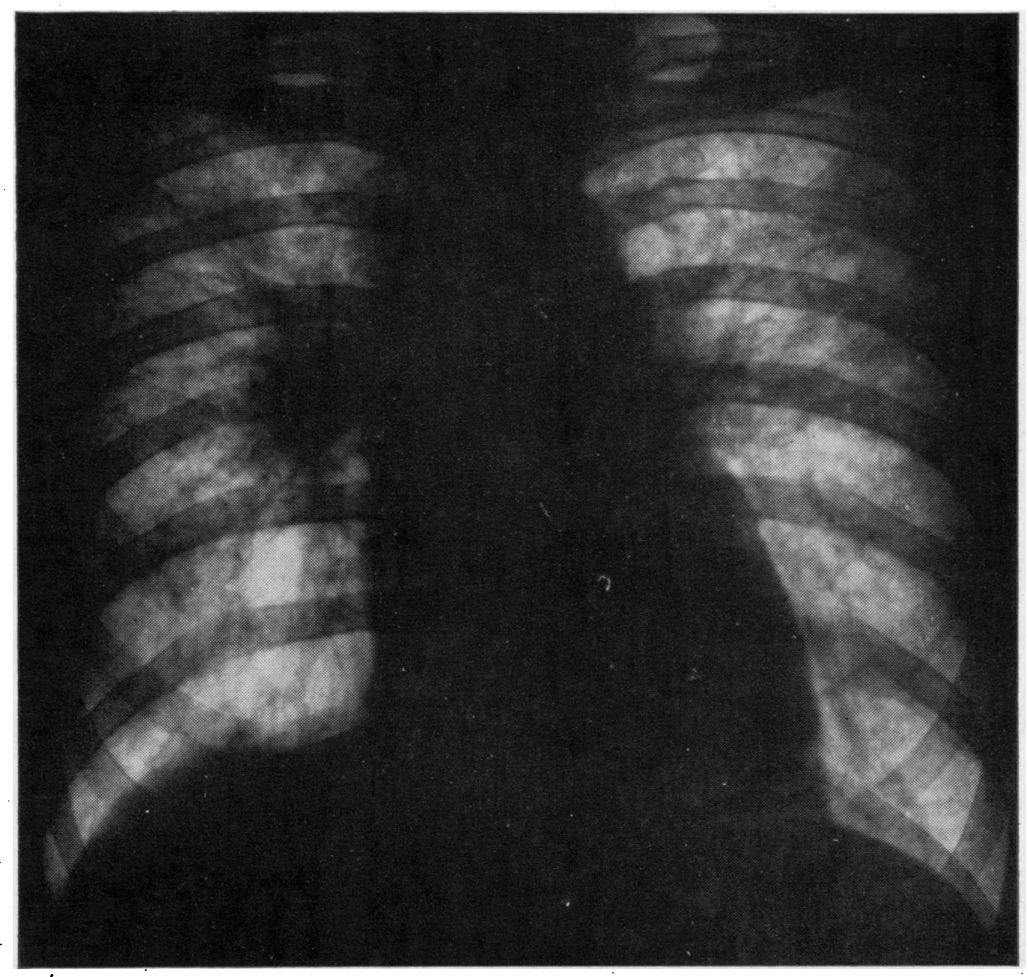

FIG. 3. Relapse occurring one month after stopping prednisone.

FiG. 4. Improvement again after a further year's treatment.

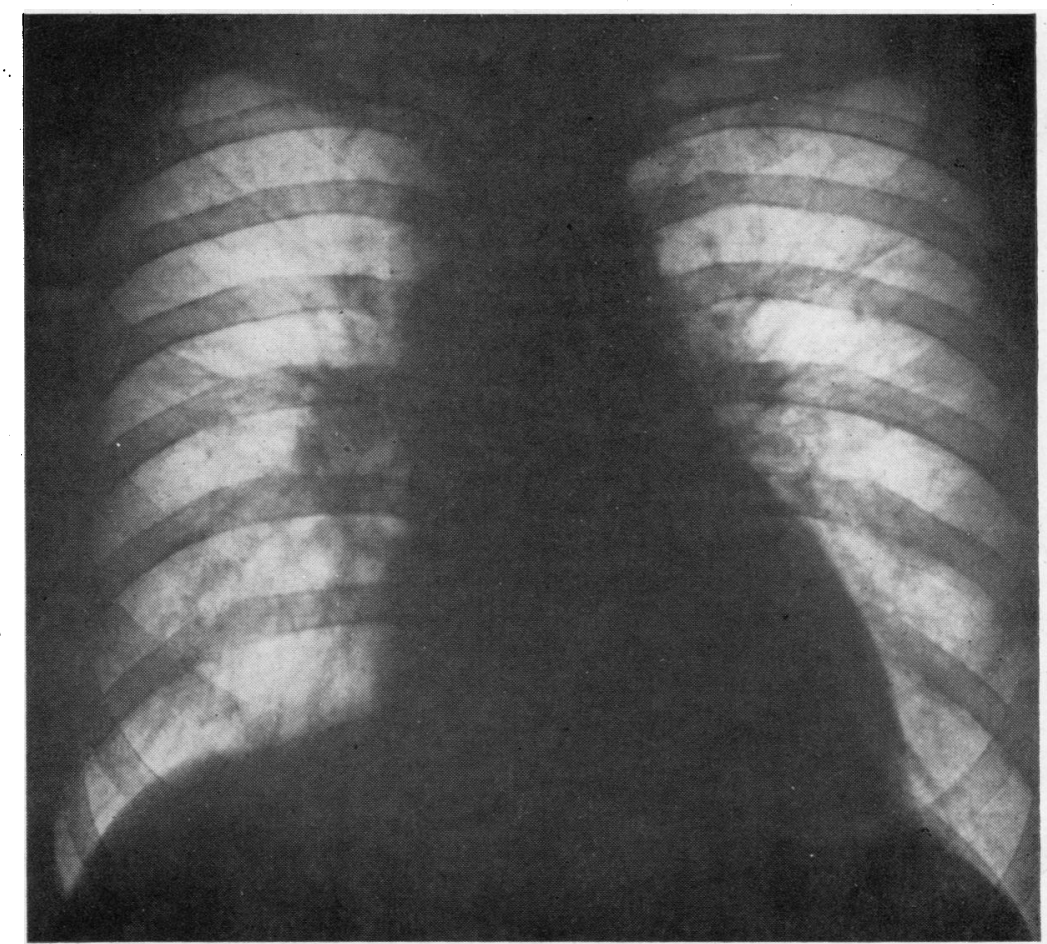


remission ; and (b) the untreated group comprised patients seen before corticosteroids were generally available and whose outcome was published (Smellie and Hoyle, 1960) before work began on the analysis of the present series, thus obviating bias on our part. Weighing the eventual outcome for this group of untreated patients against the risks and apparent benefits of treatment, we think the advantage lies with treatment.

The prime difficulty is to single out those patients who need treatment from those who do not. Better understanding of the outlook (Sones and Israel, 1961 ; Scadding, 1961 ; James, 1961 ; Löfgren and Stavenow, 1961 ; Smellie and Hoyle, 1957) has gone some way to help. It follows one of three main courses (Hoyle, 1961), each with distinctive features by which three types of the disease may be recognized. Type $I$ is benign, resolving spontaneously; type II is chronic but non-progressive ; and type III is chronic and progressive. Because the disease evolves slowly, how soon the type can be decided depends on when the patient is first seen. Early in the course, with enlarged hilar nodes and clear lung fields, it may take a full two years or more. But as most type I disease remits within this time the ultimate course may be predictable in a few months. If it takes longer, nothing is lost, as this type of the disease does not require treatment. With type II disease the answer is much more elusive. Treatment is not wanted if the disease can be clearly shown by serial review to have become arrested before doing much harm. The difficulty is to assign a patient to the correct prognostic group, either type II or III, at a time when lesions are increasing but are reversible. On this ground some patients with type II disease should be treated: they will gain a marginal improvement radiographically and perhaps in lung function, but more important they will be given some insurance against the chance that, after all, their disease may turn out to be of the dangerously progressive type III. The best guides are the serial radiographic changes-increasing density of lesions and the appearance of linear streaks and elevation of the hila, indicating progressing disease with fibrosis; the presence of exertional dyspnoea and of impairment of diffusing capacity, and of fresh sites of the disease. Patients with type III disease need treatment as soon as this decision can be made because of their bad outlook when advancing fibrosis and lung destruction stamp the type of the disease indelibly.

How long should treatment continue?
A patient whose record illustrates the problems 7 involved was a man (Mr. W. D.) of 28 found to have enlarged hilar nodes and bilateral pulmonary infiltra- $\frac{\bar{m}}{\bar{T}}$ tion by mass radiography in January 1955 . He also $\mathbb{D}$ had enlarged lymph nodes in the neck, from one of which a biopsy confirmed the diagnosis of sarcoidosis : and a bone lesion was found radiographically in a $\overrightarrow{0}$ terminal phalanx. He was mildly dyspnoeic on exertion when first seen. By March 1956 the pulmonary $\vec{\omega}$ infiltration had increased and there was also some $\stackrel{\circ}{\circ}$ radiographic evidence of fibrosis (Fig. 1). Broncho- $\overrightarrow{\vec{x}}$ scopy revealed a partially stenosed right upper lobe bronchus. Treatment with prednisone led rapidly to $N$ radiographic improvement and lessening of dyspnoea $O$ (Fig. 2). A year later, in March 1957, his treatment $\vec{\bullet}$ was gradually stopped, to be followed by deterioration within a month (Fig. 3). Treatment was restarted $\mathrm{I}$ just as an anterior segmental collapse in the right $\overrightarrow{ }$ upper lobe complicated the picture. Despite treatment $z$ this segment has remained collapsed, though, apart $\overbrace{\Phi}$ from this, radiographic improvement (Fig. 4) was again achieved. Prednisone was continued at a dose of $15 \mathrm{mg}$. daily for four years until June 1961. making a total of five years' treatment. On with- $\oplus$ drawal of steroids in 1961 there was no relapse, and serial chest radiographs up to five years later so far (October 1966) have remained unchanged.

This example suggests that the time required for treatment is that which the disease takes to run its active course. In so far as the duration of $\mathbb{Q}$ active disease decides the type in the individual, for type II disease the duration of treatment required may be expected to vary within a $\operatorname{span}$ of a few years. Type III disease requires treat ment for many years, even for life.

We are grateful to many colleagues who kindlyō referred their patients; and also to the Research Committee of King's College Hospital, who gave a: grant towards expenses.

\section{REFERENCES}

American Thoracic Society (1960). The use of corticosteroids in the treatment of sarcoidosis. Amer. Rev. resp. Dis., 82, 753.

Hamer, N. A. J. (1963). Changes in the components of the diffusing capacity in pulmonary sarcoidosis. Thorax, 18, 275.

Hoyle, C. (1961). Prognosis of pulmonary sarcoidosis. Lancet, 2, 611 Dawson, J., and Mather, G. (1955). Treatment of pulmonary sarcoidosis with streptomycin and cortisone. Ibid., 1, 638.

James, D. G. (1961). Course and prognosis of sarcoidosis. Amer Rev. resp. Dis., 84, No. 5, part 2, p. 66.

Löfgren, S., and Stavenow, S. (1961). Course and prognosis of sarN coidosis. lbid., 84, No. 5 , part 2 , p. 71 .

Marshall, R., Smellie, H., Baylis, J. H., Hoyle, C., and Bates, D. VW (1958). Pulmonary function in sarcoidosis. Thorax, 13, 48.

Scadding, J. G. (1961). Prognosis of intrathoracic sarcoidosis England. Brit. med.J., 2, 1165 .

Smellie, H., Apthorp, G. H., and Marshall, R. (1961). The effect of corticosteroid treatment on pulmonary function in sarcoidosi Thorax, 16, 87.

and Hoyle, C. (1957). The hilar lymph nodes in sarcoidosis, with special reference to prognosis. Lancet, 2, 66. Quart. J. Med., 29, 539 .

Sones, M., and Israel, H. L. (1961). Course and prognosis of sa coidosis. Amer. Rev. resp. Dis., 84, No. 5, part 2, p. 60. 